\title{
Receiver-Operating Characteristic Analysis for Evaluating the Severity of the Condition of Preterm Children Depending on Perinatal Risk Factors, Timing, and Mode of Delivery
}

\author{
Agamurad A. Orazmuradov, Phd, $\mathrm{ScD}^{1}$; Setonde Romeo D. Konnon, $\mathrm{PhD}^{1}$; \\ Nina I. Zakharova, $\mathrm{PhD}, \mathrm{ScD}^{2}$; Aleksey A. Lukaev, $\mathrm{PhD}^{2}$ \\ 'Peoples' Friendship University of Russia, Moscow, Russia \\ ${ }^{2}$ Mytishchi municipal clinical hospital, Mytishchi, Moscow Region, Russia
}

\begin{abstract}
The aim of this study was to assess the role of the receiver-operating characteristic (ROC) analysis for evaluating the severity of the condition of preterm children, depending on perinatal risk (PR) factors, timing, and mode of delivery.

In order to identify the thresholds for "intrapartum gain" of risk factors for timely selection of mode of delivery, we performed a comparative ROC analysis of the severity of the state of children at birth according to the Apgar score, from 1 point in the first minute to 7 points in the fifth minute of life. The analysis of indicators of perinatal mortality (PM) and perinatal morbidity (PMb) shows a statistically significant difference $(P<0.05)$ in the selection of the priority mode of delivery for women with premature birth during all analyzed gestation ages, depending on PR: frequency of PM and PMb is lower among pregnant women with a high risk who gave birth to premature babies delivered by C-section. (Int J Biomed. 2016;6(2):106-109.).
\end{abstract}

Key Words: perinatal mortality • perinatal morbidity• preterm delivery $\bullet$ ROC analysis • perinatal risk factors

\section{Introduction}

Premature birth (PB) is one of the most important problems in maternal and child health, as such births directly influence perinatal morbidity $(\mathrm{PMb})$ and perinatal mortality (PM). Around the world, somatic illness, implementation of the assisted reproductive technologies (ART) and the rise in the number of multiple births have led to an increased frequency of PB. The highest percentage of preterm delivery occurs between 34 and 37 weeks of gestation, while this percentage is 12 times less in the gestational period between 22 and 27 weeks. ${ }^{[1]}$

Infant mortality and child morbidity has been significantly reduced worldwide in the past 30 years. This is due to progress in the special care for premature infants. This trend is especially typical of developed countries. In the USA, the frequency of $\mathrm{PB}$ rose from $9.4 \%$ to $12.8 \%$ due to an increase in the number of multiple births on the background of ART in past 25 years. ${ }^{[2,3]}$

The outcome of PB for the newborn depends on several factors: gestational age, presence of extragenital complications,

Corresponding author: Aleksey Lukaev, PhD. Mytishchi municipal clinical hospital, Mytishchi, Moscow Region, Russia. E-mail: aleksei_lukaev@mail.ru the severity and nature of complications of pregnancy, and the type of fetal presentation. ${ }^{[4]}$

The aim of this study was to assess the role of the receiver-operating characteristic (ROC) analysis for evaluating the severity of the condition of preterm children, depending on perinatal risk (PR) factors, timing, and mode of delivery.

\section{Materials and Methods}

The study was carried out in CMH № 29 named after N.E. Bauman. We carried out a prospective analysis of 236 medical records of pregnant women at 28 to 33 weeks (plus 6 days) of gestation. According to PB classification, all pregnant women were divided into 2 cohorts: Cohort 1 (gestational age from 28 to 30 weeks plus 6 days) and Cohort 2 (gestational age from 31 to 33 weeks plus 6 days). At admission, every patient was evaluated for PR factors. Depending on the amount of PR factors, each cohort was divided into 3 groups: Group 1 (low risk), Group 2 (moderate risk), and Group 3 (high risk).

We identified the degree of PR based on the scale developed by O. G. Frolova and E. I. Nikolaeva (1981) and modified by V. E. Radzinsky et al. ${ }^{[5]}$ The scale includes a number of parameters divided into blocks: socio-biological block, data of obstetric and gynecological history, extragenital diseases of mother, complications of pregnancy, and fetal 
assessment. A specific group for PR was defined in accordance with the number of points derived from S. Knyazev's scale (2003). Low risk ( $<15$ points), moderate risk (from 15 to 20 points), and high risk ( $>25$ points). Calculation of PR factors was performed twice: at admission and during labor. The ratio of these indexes determines the so-called "intrapartum gain" (IG) of PR factors.

Statistical analysis was performed using the SPSS for Windows. Baseline characteristics were summarized as frequencies and percentages for categorical variables and as mean (M) and standard error of the mean (SEM) for continuous variables. Group comparisons with respect to categorical variables are performed using chi-square test. A probability value of $P<0.05$ was considered statistically significant. ROC analysis was performed using MedCalc.

\section{Results and Discussion}

At admission to the maternity hospital, all pregnant women underwent tocolytic therapy, including intrapartum tocolysis or treatment with magnesium sulfate.

Vaginal birth occurred in $65.3 \%$ of surveyed women, and Cesarean delivery was performed in $34.7 \%$. Evaluation of indications for abdominal delivery in pregnant women with preterm pregnancy showed that $19.5 \%$ had a low PR, $39.0 \%$ had a moderate PR, and $41.5 \%$ a high PR. The main indications for operative delivery were the progression of gestational toxicosis $(22 \%)$, abnormal fetal position $(22 \%)$, and acute hypoxia (18.3\%).

In order to identify the thresholds for IG of risk factors for timely selection of mode of delivery, we performed a comparative ROC analysis of the severity of the state of children at birth according to the Apgar score (AS), ${ }^{[6,7]}$ from 1 point in the first minute to 7 points in the fifth minute of life (Table 1).

Table 1.

Number of newborns with AS from 1 to 7 points

\begin{tabular}{|c|c|c|c|c|c|c|c|c|}
\hline \multirow[t]{2}{*}{ ํㅡㅇ } & \multirow[t]{2}{*}{$\begin{array}{l}\text { Degree } \\
\text { of PR }\end{array}$} & \multirow[t]{2}{*}{$\mathrm{n}$} & \multicolumn{3}{|c|}{$\begin{array}{l}\text { Newborns with an AS } \\
\text { of } 1 \text { point on the } 1 \mathrm{st} \\
\text { minute to } 7 \text { points on } \\
\text { the } 5 \text { th minute of life }\end{array}$} & \multicolumn{3}{|c|}{$\begin{array}{c}\text { Number of } \\
\text { deaths }\end{array}$} \\
\hline & & & $\mathrm{n}$ & $\%$ & & & & \\
\hline \multirow{3}{*}{ I } & low & 20 & 4 & 20,0 & & & & \\
\hline & moderate & 38 & 12 & 31,6 & & & & \\
\hline & high & 70 & 24 & 34,3 & & & & \\
\hline \multirow{3}{*}{ II } & low & 32 & 13 & 40,6 & & & & \\
\hline & moderate & 52 & 17 & 32,7 & & & & \\
\hline & high & 24 & 8 & 33,3 & & & & \\
\hline \multicolumn{9}{|c|}{ Summarized } \\
\hline \multirow{2}{*}{$\begin{array}{l}\text { Degree } \\
\text { of } \\
\text { PR }\end{array}$} & \multirow[t]{2}{*}{ Total } & \multicolumn{5}{|c|}{$\begin{array}{l}\text { Newborns with an AS of } 1 \text { point } \\
\text { on the } 1 \text { st minute to } 7 \text { points } \\
\text { on the 5th minute of life }\end{array}$} & \multicolumn{2}{|c|}{$\begin{array}{l}\text { Number of } \\
\text { deaths }\end{array}$} \\
\hline & & \multicolumn{2}{|r|}{$\mathrm{n}$} & \multicolumn{2}{|c|}{$\%$} & & $\mathrm{n}$ & $\%$ \\
\hline low & 52 & \multicolumn{2}{|r|}{17} & \multicolumn{2}{|c|}{32.7} & & 1 & 1.9 \\
\hline moderate & 90 & \multicolumn{2}{|r|}{29} & \multicolumn{2}{|c|}{32.2} & & 5 & 5.6 \\
\hline high & 94 & \multicolumn{2}{|r|}{32} & \multicolumn{2}{|c|}{34.0} & & 2 & 2.1 \\
\hline
\end{tabular}

Note: No statistically significant differences $(P>0.05)$.
The prognostic value of IG for risk factors for PMb and PM was obtained by assessing the area under the curve (AUC): 0.9-1.0, excellent; 0.8-0.9, very good; $0.7-0.8$, good; $0.6-0.7$, tolerable; and $<0.6$, deficient. ${ }^{[8,9]}$

1. For pregnant women with a low PR, AUC was $0.821 \pm 0.062$ and the studied model could be evaluated as very good, which predicted a probability of childbirth with a low AS due to a high level of $\mathrm{PMb}$, depending on the increase in points. The cut-off level was an IG of $51.5 \%$ with diagnostic sensitivity of $82.4 \%$ and specificity of $88.6 \%$. The total number of newborns with an AS of 1 to 7 points was 52, including 17 with a low AS. Under the threshold of 51.5\%, we identified 34 newborns, including 3 newborns with a low AS. Among 18 newborns from mothers with an IG more than $51.5 \%, 14$ had a low AS (Figure 1, Tables 2 and 3).

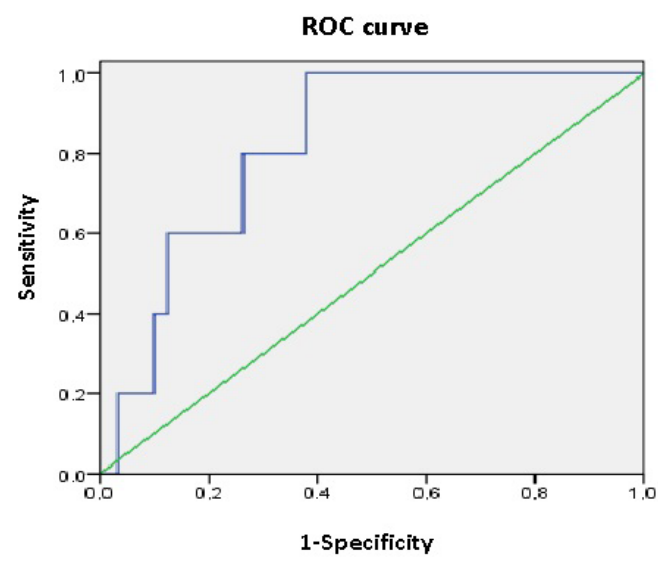

Fig. 1. ROC curve for $A S$ and $I G(51.5 \%)$

Table 2.

Prognostic value of IG for risk factors for PMb and PM

\begin{tabular}{|c|c|c|c|}
\hline \multicolumn{2}{|l|}{ Test Results } & $\begin{array}{c}\text { Number of newborns with } \\
\text { an AS of } 1 \text { to } 3 \text { points }\end{array}$ & $\begin{array}{c}\text { Number of newborns with } \\
\text { an AS of } 4 \text { to } 7 \text { points }\end{array}$ \\
\hline \multirow{2}{*}{ IG } & $>51.5 \%$ & 14 & 4 \\
\cline { 2 - 4 } & $<51.5 \%$ & 3 & 31 \\
\hline
\end{tabular}

\begin{tabular}{|l|l|}
\hline sensitivity & $82.4 \%$ \\
\hline specificity & $88.6 \%$ \\
\hline accuracy & $86.5 \%$ \\
\hline
\end{tabular}

Table 3.

Area under the curve

\begin{tabular}{|c|c|c|c|c|}
\hline \multirow{2}{*}{ Area } & \multirow{2}{*}{$\begin{array}{c}\text { Standard } \\
\text { error }\end{array}$} & \multirow{2}{*}{$\begin{array}{c}\text { Asymptotic } \\
\text { significance }\end{array}$} & \multicolumn{2}{|c|}{ Asymptotic 95\% CI } \\
\cline { 4 - 5 } & & lower limit & upper limit \\
\hline .821 & .062 & .015 & .700 & .942 \\
\hline
\end{tabular}


2. For pregnant women with a moderate PR, AUC was $0,754 \pm 0,063$ and the studied model could be evaluated as good, which predicted a probability of childbirth with a low AS due to a high level of $\mathrm{PMb}$, depending on the increase in points. The cut-off level was an IG of $39.5 \%$. The total number of newborns with an AS of 1 to 7 points was 90, including 29 with severe asphyxia. Under the threshold of $39.5 \%$, we identified 27 newborns, including 23 newborns with severe asphyxia (Figure 2, Tables 4 and 5).

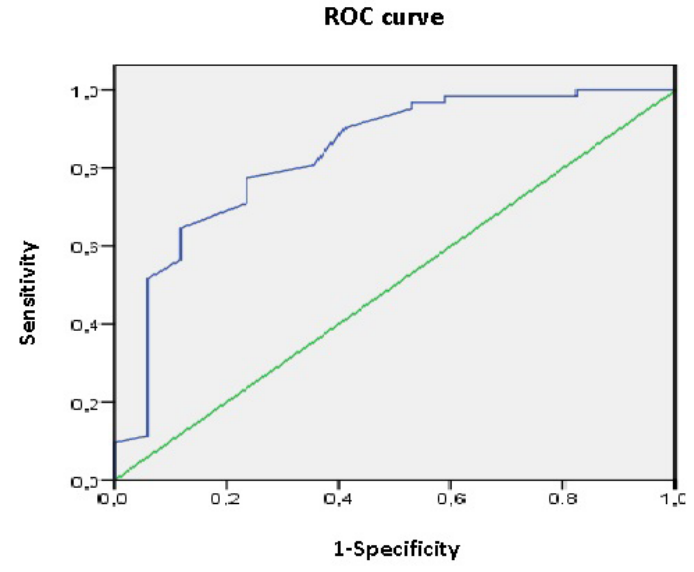

Fig. 2. ROC curve for $A S$ and $I G(39.5 \%)$

Table 4.

Prognostic value of IG for risk factors for PMb and PM

\begin{tabular}{|c|c|c|c|}
\hline \multicolumn{2}{|c|}{$\begin{array}{c}\text { Test } \\
\text { Results }\end{array}$} & $\begin{array}{c}\text { Number of newborns with } \\
\text { an AS of } 1 \text { to 3 points }\end{array}$ & $\begin{array}{c}\text { Number of newborns with } \\
\text { an AS of } 4 \text { to } 7 \text { points }\end{array}$ \\
\hline \multirow{2}{*}{ IG } & $>39.5 \%$ & 23 & 4 \\
\cline { 2 - 4 } & $<39.5 \%$ & 6 & 31 \\
\hline
\end{tabular}

\begin{tabular}{|l|l|}
\hline sensitivity & $79.3 \%$ \\
\hline specificity & $88.6 \%$ \\
\hline accuracy & $84.4 \%$ \\
\hline
\end{tabular}

Table 5.

Area under the curve

\begin{tabular}{|c|c|c|c|c|}
\hline \multirow{2}{*}{ Area } & \multirow{2}{*}{$\begin{array}{c}\text { Standard } \\
\text { error }\end{array}$} & \multirow{2}{*}{$\begin{array}{c}\text { Asymptotic } \\
\text { significance }\end{array}$} & \multicolumn{2}{|c|}{ Asymptotic 95\% CI } \\
\cline { 4 - 5 } & & lower limit & upper limit \\
\hline .754 & .063 & .001 & .630 & .877 \\
\hline
\end{tabular}

3. For pregnant women with a high PR, AUC was $0,889 \pm 0,052$ and the studied model could be evaluated as very good, which predicted a probability of childbirth with a serious condition, depending on the increase in points. The cut-off level was an IG of $30.5 \%$. The total number of newborns with an AS of 1 to 7 points was 94, including 32 newborns with a low AS. Under threshold less of $30.0 \%$, we defined 35 newborns, including 24 newborns with a low AS (Figure 3, Tables 6 and 7).

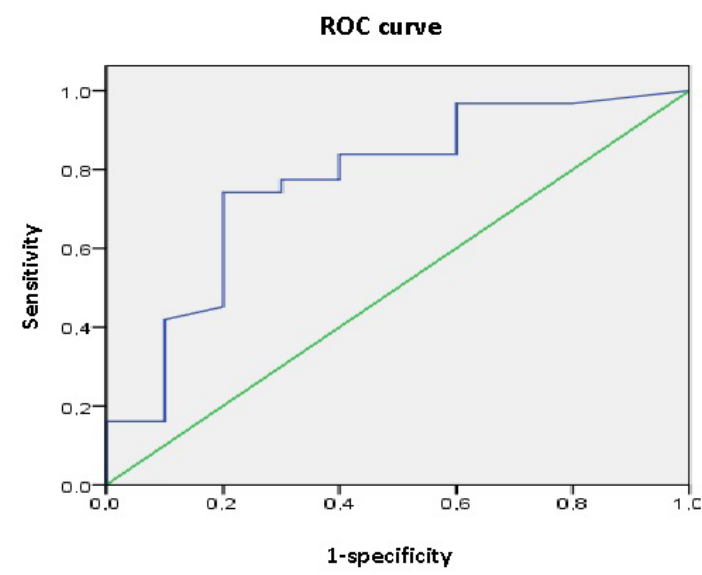

Fig. 3. ROC curve for $A S$ and $I G(30.0 \%)$

Table 6.

Prognostic value of IG for risk factors for PMb and PM

\begin{tabular}{|c|c|c|c|}
\hline \multicolumn{2}{|c|}{$\begin{array}{c}\text { Test } \\
\text { Results }\end{array}$} & $\begin{array}{c}\text { Number of newborns with } \\
\text { an AS of 1 to 3 points }\end{array}$ & $\begin{array}{l}\text { Number of newborns with } \\
\text { an AS of 4 to 7 points }\end{array}$ \\
\hline \multirow{3}{*}{ IG } & $30.0 \%$ & 8 & 51 \\
\cline { 2 - 4 } & $<30.0 \%$ & 24 & 11 \\
\hline
\end{tabular}

\begin{tabular}{|l|l|}
\hline sensitivity & $75.0 \%$ \\
\hline specificity & $82.3 \%$ \\
\hline accuracy & $79.8 \%$ \\
\hline
\end{tabular}

Table 7.

Area under the curve

\begin{tabular}{|c|c|c|c|c|}
\hline \multirow{2}{*}{ Area } & \multirow{2}{*}{$\begin{array}{c}\text { Standard } \\
\text { error }\end{array}$} & \multirow{2}{*}{$\begin{array}{c}\text { Asymptotic } \\
\text { significance }\end{array}$} & \multicolumn{2}{|c|}{ Asymptotic 95\% CI } \\
\cline { 4 - 5 } & & lower limit & upper limit \\
\hline .889 & .052 & .000 & .787 & .991 \\
\hline
\end{tabular}

Thus, the predicted relative risk of delivering a child with a low AS and a predictable PM among women with a low PR corresponds to IG $>51.5 \%$ ( $R R=3.20,95 \%$ CI:3.20-1.75) (Table 8). The predicted relative risk of delivering a child with a low AS and a predictable PM among women with a moderate PR corresponds to $\mathrm{IG}>39.5 \%$ ( $\mathrm{RR}=5.38,95 \% \mathrm{CI}: 2.86-10.11)$ (Table 9). The predicted relative risk of delivering a child with a low AS and a predictable PM among women with a high PR corresponds to $\mathrm{IG}>30 \%(\mathrm{RR}=4.23,95 \% \mathrm{CI}: 2.39-7.49)$ (Table 10). 
Table 8.

Predicted relative risk of delivering a child with a low AS and a predictable PM among women with a low PR

\begin{tabular}{|c|c|c|c|c|c|}
\hline \multirow{2}{*}{ IG } & \multicolumn{2}{|c|}{ AS of 1 to 3 points } & \multicolumn{2}{|c|}{ AS of 4 to 7 points } & \multirow{2}{*}{$P$} \\
\cline { 2 - 5 } & $\mathrm{n}$ & $\%$ & $\mathrm{n}$ & $\%$ & \\
\hline$>51.5 \%$ & 14 & 77.8 & 4 & 22.2 & $<0.001$ \\
\hline$<51.5 \%$ & 3 & 8.8 & 31 & 91.2 & $<0.001$ \\
\hline
\end{tabular}

Table 9.

Predicted relative risk of delivering a child with a low AS and a predictable PM among women with a moderate PR

\begin{tabular}{|c|c|c|c|c|c|}
\hline \multirow{2}{*}{ IG } & \multicolumn{2}{|c|}{ AS of 1 to 3 points } & \multicolumn{2}{|c|}{ AS of 4 to 7 points } & \multirow{2}{*}{$P$} \\
\cline { 2 - 5 } & $\mathrm{n}$ & $\%$ & $\mathrm{n}$ & $\%$ & \\
\hline$>39.5 \%$ & 6 & 9.5 & 57 & 90.5 & $<0.001$ \\
\hline$<39.5 \%$ & 23 & 85.2 & 4 & 14.8 & $<0.001$ \\
\hline
\end{tabular}

Table 10.

Predicted relative risk of delivering a child with a low AS and a predictable PM among women with a high PR

\begin{tabular}{|c|c|c|c|c|c|}
\hline \multirow{2}{*}{ IG } & \multicolumn{2}{|c|}{ AS of 1 to 3 points } & \multicolumn{2}{|c|}{ AS of 4 to 7 points } & \multirow{2}{*}{$P$} \\
\cline { 2 - 5 } & $\mathrm{n}$ & $\%$ & $\mathrm{n}$ & $\%$ & \\
\hline$>30.0 \%$ & 8 & 13.6 & 51 & 86.4 & $<0.001$ \\
\hline$<30.0 \%$ & 24 & 68.6 & 11 & 31.4 & $<0.01$ \\
\hline
\end{tabular}

\section{Conclusion}

Thus, the analysis of indicators of PM and PMb shows a statistically significant difference $(P<0.05)$ in the selection of the priority mode of delivery for women with premature birth during all analyzed gestation ages, depending on PR: frequency of PM and PMb is lower among pregnant women with a high risk who gave birth to premature babies delivered by $\mathrm{C}$-section. A C-section for preterm labor at the gestational age of 28-33 weeks ( +6 days) should be considered if IG is:

- $>50 \%(\mathrm{RR}=3.20,95 \% \mathrm{CI}: 3.20-1.75)$ for a low PR

- > 40\% (RR $=5.38,95 \%$ CI:2.86-10.11) for a moderate PR

- > 30\% (RR=4.23, 95\% CI:2.39-7.49) for a high PR.

\section{Competing interests}

The authors declare that they have no competing interests.

\section{References}

1. Baranov II, Skripnichenko YuP, Tokova ZZ, Kuz'mich IN.Medical and social aspects of preterm birth. Gynecology. 2014;5:90-93. [Article in Russian].

2. Ahmed AH, Sands LP. Effect of pre- and postdischarge interventions on breastfeeding outcomes and weight gain among premature infants. J Obstet Gynecol Neonatal Nurs. 2010;39(1):53-63.

3. Martin JA; Centers for Disease Control and Prevention (CDC). Preterm births - United States, 2007. MMWR Suppl. 2011 Jan 14; 60(1):78-9.

4. Maldybaeva EK, Dolgaya GV, Turdieva AS, Sarymsakova TA. Retrospective analysis of perinatal outcomes in women with preterm delivery. Vestnik KRSU. 2015; 15(4): 67-69.

5. Radzinsky VE, Knyazev CA, IN Kostin. Obstetric risk. Maximum of information - Mminimum of danger to the mother and baby. M.: Eksmo; 2009, 290 pp. [in Russian].

6. Apgar V. A proposal for a new method of evaluation of the newborn infant. Curr Res Anesth Analg. 1953;32:260-7.

7. The Apgar score. ACOG Committee Opinion No. 333. American Academy of Pediatrics; American College of Obstetricians and Gynecologists. Obstet Gynecol 2006;107:1209-12.

8. Florkowski CM. Sensitivity, specificity, receiveroperating characteristic (ROC) curves and likelihood ratios: communicating the performance of diagnostic tests. Clin Biochem Rev. 2008; 29 Suppl 1:S83-7.

9. Akobeng AK. Understanding diagnostic tests 3: Receiver operating characteristic curves. Acta Paediatr. 2007; 96(5):644-7. 